\title{
Deep-LSTM ensemble framework to forecast Covid-19: an insight to the global pandemic
}

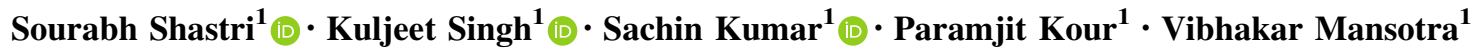

Received: 15 September 2020/Accepted: 12 November 2020/Published online: 3 January 2021

(C) Bharati Vidyapeeth's Institute of Computer Applications and Management 2021

\begin{abstract}
The pandemic of Severe Acute Respiratory Syndrome Coronavirus 2 (SARS-CoV-2) is spreading all over the world. Medical health care systems are in urgent need to diagnose this pandemic with the support of new emerging technologies like artificial intelligence (AI), internet of things (IoT) and Big Data System. In this dichotomy study, we divide our research in two waysfirstly, the review of literature is carried out on databases of Elsevier, Google Scholar, Scopus, PubMed and Wiley Online using keywords Coronavirus, Covid-19, artificial intelligence on Covid-19, Coronavirus 2019 and collected the latest information about Covid-19. Possible applications are identified from the same to enhance the future research. We have found various databases, websites and dashboards working on real time extraction of Covid-19 data. This will be conducive for future research to easily locate the available information. Secondly, we designed a nested ensemble model using deep learning methods based on long short term memory (LSTM). Proposed Deep-
\end{abstract}

Vibhakar Mansotra: Mentor.

Sourabh Shastri

sourabhshastri@gmail.com

Kuljeet Singh

kuljeetshan94@gmail.com

Sachin Kumar

skh.sachinkumar@gmail.com

Paramjit Kour

param.kour.94@gmail.com

Vibhakar Mansotra

vibhakar20@yahoo.co.in

1 Department of Computer Science and IT, University of Jammu, Jammu, Jammu and Kashmir 180006, India
LSTM ensemble model is evaluated on intensive care Covid-19 confirmed and death cases of India with different classification metrics such as accuracy, precision, recall, f-measure and mean absolute percentage error. Medical healthcare facilities are boosted with the intervention of AI as it can mimic human intelligence. Contactless treatment is possible only with the help of AI assisted automated health care systems. Furthermore, remote location self treatment is one of the key benefits provided by AI based systems.

Keywords LSTM · Covid-19 · Deep learning · Artificial intelligence $\cdot$ Nested ensemble

\section{Introduction and background}

The coronavirus cases were firstly reported in 1960 and around 500 patients were identified with flu and out of them, 18 were infected by coronavirus. Until 2002, coronavirus was treated as a simple non fatal disease and from 2003 onwards various research reports were published about increasing cases of coronavirus in many countries. Severe acute respiratory syndrome (SARS) caused by coronavirus led to 1000 deaths in 2003 and about 8000 patients were infected with coronavirus. Moreover, 50 patients of severe acute respiratory syndrome (SARS) were also confirmed by a Hong Kong study report in which 30 patients were infected with coronavirus and correspondingly in 2004, World Health Organization (WHO) declared the state emergency in infected countries [1]. In 2012, Saudi Arabia also reported some confirmed cases and deaths [2, 3]. In late December 2019, few patients were identified with pneumonia symptoms in Wuhan city (capital city of Hubei Province in China). Out of them, few 
patients worked at the local Huanan seafood wholesale market in which live animals were also on sale $[4,5]$. At a very early stage of this pneumonia, severe acute respiratory infection occurred which led to acute respiratory system failure or acute respiratory distress syndrome (ARDS).

Coronaviruses belong to the subfamily of Coronaviridae and are single strand positive RNA viruses that can be subgrouped as alpha, beta, gamma and delta [6-8]. There are four common human coronaviruses namely (i) 229E (alpha coronavirus) (ii) NL63 (alpha coronavirus) (iii) OC43 (beta coronavirus) (iv) HKU1 (beta coronavirus). MERS-COV and SARS-COV are the beta coronaviruses that cause Middle East Respiratory Syndrome (MERS) and Severe Acute Respiratory Syndrome (SARS) respectively. SARSCOV-2 is the novel coronavirus that results 2019-nCov, coronavirus disease 2019 or Covid-19 [9-11].

About 215 countries and regions were affected due to this pandemic $[12,13]$ and is a global threat to mankind on earth. The cause of the spread of Covid-19 pandemic is lack of AI assisted automated diagnostic systems. As the pandemic is spreading via human to human contact, there is an urgent need for contactless treatment to save lives. The purpose of this study is to inculcate knowledge about Covid-19 pandemic through various databases, websites and experiments done so far and to diagnose Covid-19 using proposed deep-LSTM ensemble model. To the best of our knowledge and experience from the literature review, all the information propagated through present research work along with proposed deep learning based experimentation was not done before. This can also help future research direction to use collective information. This paper focuses on the role of Artificial Intelligence to combat Covid-19 pandemic.

The remainder of this paper is arranged as follows: In Sect. 2, we discuss the applications of AI to detect and diagnose Covid-19. In Sect. 3, various Covid-19 datasets along with websites and current pandemic situations are discussed. In Sect. 4, there is research methodology discussed with data description, experiment and results. In Sect. 5, the author's contribution to defeat Covid-19 pandemic is tabulated. In Sect. 6, the discussion and conclusion is elaborated.

\section{Artificial intelligence in diagnosing Covid-19}

Artificial intelligence (AI) will play a vital role in diagnosing the global pandemic presently known as COVID19. The contribution and analytics of artificial intelligence in the fields of Medical Imaging, Natural Language Processing, Text Mining, Deep Learning, Machine Learning, Expert Systems, Data Analytics and Internet of Things are unprecedented and keen to be appreciable. As the time passes, AI is becoming more dominant in public health sectors. Some applications of AI in diagnosing Covid-19 are mentioned below.

\subsection{AI based mobile and web applications}

Artificial Intelligence can easily chase the spread of this deadly virus and also assist to identify the high risk patients with coronavirus symptoms. Along with the extensive review in this paper, we also generalized the architecture of symptomatic analysis with AI and normal approach as shown in Fig. 1 where we differentiate between the therapy given by AI systems and normal human manual approach. AI systems don't require taking multiple sample reports of Covid-19 patients manually whereas in Non-AI systems, the risk of health care workers to get infected is quite high [14]. As per the recent reports, 200 front line workers (including doctors and nurses) died on $3^{\text {rd }}$ May 2020 in Black, Asian and Minority Ethnic (BAME) groups [15].

Artificial Intelligence can contribute to global health initiatives that are built across multiple tools such as to predict the healing time of the skin burn by using photographs on smart phones and tools which can accurately predict the pregnancy related complications discussed in $[16,17]$. Similar kind of work is done by [18] and predicts the mortality rate of the patients using various machine learning algorithms with 93\% accuracy. Authors in [19] also predicts the transmission dynamics of the coronavirus which leads to medical health strategy and policy making. To track, detect and predict the Covid-19 in real time, several data repository initiatives were taken at global level including a dashboard designed by Johns Hopkins Center for Systems Science and Engineering (CSSE) [20, 21]. Another dashboard is designed as HealthMap Covid-19 with participant institutions such as Oxford University is available at [22-24].

A web application is designed based on susceptible-infected-recovered (SIR) model with exposed individuals as additional category [25]. The application is available at [26] and the source code is also available at Github repository in [27]. An app was developed by University of Melbourne as Coronavirus 10-day forecast which updates daily data on Covid-19 based on country wise data collected by Johns Hopkins University and Ministry of Health and Family Welfare, Government of India datasets and is available at [28] and the code is also available at Github [29]. A web application is designed by [30] to track real time mutational status of Covid-19 and enable users to annotate their genomic sequences on Covid-19 globally. The web application is available at [31] and source code available at Github [32]. An Artificial Intelligence (AI) based mobile app AI4 VIVID-19 is designed to test Covid19 symptoms with just a couple of cough recording 


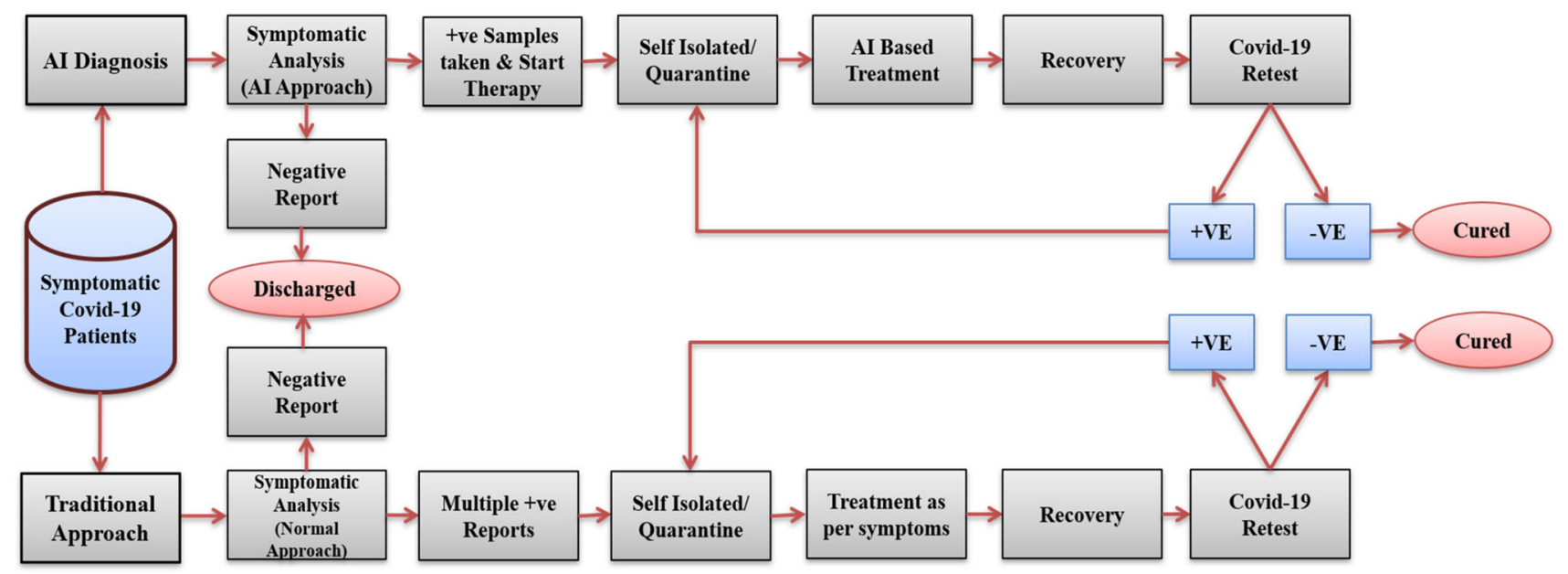

Fig. 1 Generalized architecture of AI and normal symptomatic analysis

samples. This app distinguishes between Covid-19 and Non-Covid-19 patients with 90\% accuracy [33]. COVIDMobileXpert is a lightweight mobile app designed by [34] using Deep Neural Networks and uses snapshots of chest $\mathrm{X}$-ray for screening Covid-19.

\subsection{AI based treatment using medical images}

After detection and prediction of Covid-19 symptoms, there is a need to diagnose this severe disease using AI in a leading role. With an extensive literature review, we came to know various AI based algorithms which can detect as well as diagnose Covid-19 patients successfully. An overview is also given in Fig. 2 about how AI came into contact with the coronavirus pandemic. Study shows a positive correlation between coronavirus (Covid-19), mortality and morbidity rate, burden over radiologists and health care facilities [35].

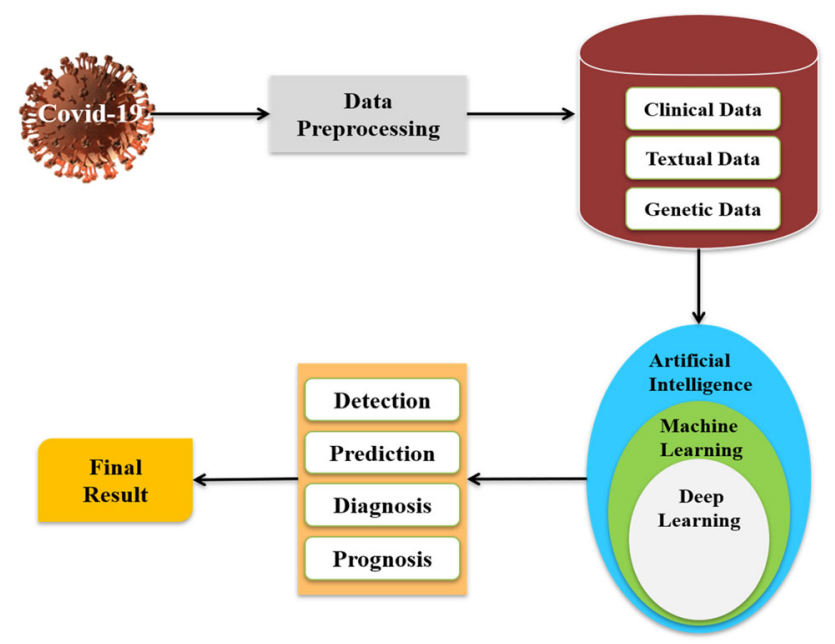

It is nearly impossible in large countries like India and China to train a huge number of healthcare workers including nurses and doctors in the midst of pandemic. Its solution is to design intelligent AI machines that can mimic human intelligence. Transfer learning mechanism is being used in $[36,37]$ to design deep CNN based decompose, transfer, and compose (DeTraC) models with 95.12\% accuracy. niclosamide and promazine are two active drugs for SARS-CoV in [38] which designed two AI models by combining different datasets from approved drugs. Authors in [39] designed a model for mask wearing face detection using AI. Work in $[40,41]$ shows that AI can recognize breathing characteristics of a Covid-19 patient and distinguish it with non-Covid-19 person. Respiratory simulation model (RSM) is being used to simulate training and real world data and deep learning is being used to classify 6 clinical respiratory patterns. Authors in [42] proposed a Convolutional neural network based model viz. CoroNet which detects Covid-19 using x-ray images of the chest. Covid-19 gets confirmed by respiratory gene sequencing samples which is a key factor for reverse transcription polymerase chain reaction (RT-PCR) [40]. In [43, 44] authors make use of chest CT images and designed AI based automated systems for segmentation of all lung infections. Authors in [45] studies about MERS CoV and explored the features of chest CT and X-ray images which resemble pneumonia. CT scanning is an advanced version of X-ray machines which gives clearer image and softens the inner tissues and organs [46]. By combining AI with IoT, we can achieve contactless diagnosis and streaming of Covid-19 [47, 48]. This can be panacea for the front line workers as they are the first target during this pandemic. To make equilibrium between these two situations, cognitive internet of medical things (CIoMT) helps the doctors to

Fig. 2 Leading role of artificial intelligence 
Table 1 Distinguished Covid-19 datasets

\begin{tabular}{|c|c|c|c|c|}
\hline $\begin{array}{l}\text { S. } \\
\text { no. }\end{array}$ & Reference & Dataset name & Country & Type(s) of data \\
\hline 1 & {$[52]$} & Kinsa Smart Thermometer Weather Map & USA & Temperature readings \\
\hline 2 & {$[53]$} & RKI COVID19 & Germany & Infection cases \\
\hline 3 & {$[54]$} & BSTI Covid-19 Imaging Database & UK & CT scan \\
\hline 4 & {$[55]$} & COVID-19 DATABASE & Italy & Radiological data \\
\hline 5 & {$[56]$} & nCoV2019 & 7 countries & Epidemiological data \\
\hline 6 & {$[57]$} & Data-Science-for-COVID-19 & Korea & Patient demographics \\
\hline 7 & {$[58]$} & covid-19-data & USA & Live data \\
\hline 8 & [59] & covid-chestxray-dataset & Italy & Patient demographics \\
\hline 9 & {$[60]$} & RCSB Protein Data Bank & $\begin{array}{l}\text { All } \\
\text { countries }\end{array}$ & Genomic sequences \\
\hline 10 & {$[61]$} & COVID-CT-Dataset & $\begin{array}{l}\text { All } \\
\text { countries }\end{array}$ & Labeled chest CT scans \\
\hline 11 & {$[62]$} & Public Corona-virus Twitter Dataset & $\begin{array}{l}\text { All } \\
\text { countries }\end{array}$ & Twitter ID's \\
\hline 12 & {$[63]$} & COVID-19 Community Mobility Reports & $\begin{array}{l}135 \\
\text { countries }\end{array}$ & Community Mobility Report \\
\hline 13 & {$[64]$} & Novel Corona-virus 2019 dataset & $\begin{array}{l}\text { All } \\
\text { countries }\end{array}$ & Patient demographics \\
\hline 14 & {$[65]$} & $\begin{array}{l}\text { COVID-19 Open Research Dataset Challenge } \\
\text { (CORD-19) }\end{array}$ & $\begin{array}{l}\text { All } \\
\text { countries }\end{array}$ & Research articles dataset \\
\hline 15 & {$[66,67]$} & LitCovid & $\begin{array}{l}\text { All } \\
\text { countries }\end{array}$ & Research articles dataset \\
\hline 16 & {$[68]$} & Coronavirus Source Data & $\begin{array}{l}\text { All } \\
\text { countries }\end{array}$ & Time series data \\
\hline 17 & {$[69]$} & JHU CSSE COVID-19 Data & $\begin{array}{l}\text { All } \\
\text { countries }\end{array}$ & $\begin{array}{l}\text { Mortality count, cured patient count, confirmed cases, } \\
\text { location }\end{array}$ \\
\hline 18 & {$[70]$} & Coronavirus COVID19 Tweets & $\begin{array}{l}\text { All } \\
\text { countries }\end{array}$ & Tweet text, hashtags, location \\
\hline 19 & [71] & hCOV-19 & $\begin{array}{l}\text { All } \\
\text { countries }\end{array}$ & genomic epidemiology \\
\hline 20 & {$[72]$} & CHIME & $\begin{array}{l}\text { All } \\
\text { countries }\end{array}$ & Susceptible, infected and recovered patient count \\
\hline 21 & {$[73]$} & Global research on COVID-19 & $\begin{array}{l}\text { All } \\
\text { countries }\end{array}$ & Research articles dataset \\
\hline
\end{tabular}

diagnose patients remotely via wearable IoT sensors [49, 50].

\section{AI working with Covid-19 data repository}

Data is new fuel to modern world technologies like Artificial Intelligence, Data Science, Big Data, Blockchain and IoT. Without data these algorithms are of no use. AI algorithms required data to learn and analyze the sequences to give desired output. Author in [51] mentioned the importance of data for AI to train models for better prediction.

\subsection{Data sources of Covid-19}

Table 1 Shows prominent datasets used to monitor Covid19 studies whereas Table 2 show websites and community resources of Covid-19 to spread information about the pandemic and to monitor real time status of Covid-19 globally.

\subsection{Current country wise situation}

Table 3 Shows Covid-19 status of top 10 countries ordered in terms of confirmed, death, recovered and active cases. These countries are most affected due to the pandemic and 
Table 2 Distinguished Covid-19 websites and community resources

\begin{tabular}{|c|c|c|}
\hline $\begin{array}{l}\text { S. } \\
\text { no. }\end{array}$ & Website & Description \\
\hline 1 & $\begin{array}{l}\text { CSSE at JHU and } \\
\text { Dashboard }\end{array}$ & $\begin{array}{l}\text { Covid-19 website by Center for Systems Science and Engineering (CSSE) at Johns Hopkins University (JHU) } \\
\text { and in dashboard it shows country wise status of Covid-19 }\end{array}$ \\
\hline 2 & $\begin{array}{l}\text { MATLAB for Deep } \\
\text { Learning }\end{array}$ & Deep Learning technique is applied to detect Covid-19 using chest radiographic images in MATLAB \\
\hline 3 & Partnership on AI & Collaborative efforts to discover Datasets and Webinars \\
\hline 4 & $\begin{array}{l}\text { Global research database } \\
\text { (WHO) }\end{array}$ & To accelerate the research process and develop new norms aimed Covid-19 pandemic \\
\hline 5 & Telehealth Toolbox & Online diagnosis of Covid-19 having telemedicine platform \\
\hline 6 & Vector Institute & Online platform to know about various resources of Covid-19 \\
\hline 7 & Montreal AI task force & Open and shared antiviral agent for Covid-19 \\
\hline 8 & LitCovid & Up to date information on Covid-19 and central access to more than 21,996 articles on Covid- 19 on PubMed \\
\hline 9 & Covid-19 Data Portal & $\begin{array}{l}\text { European Molecular Biology Lab-European Bioinformatics Institute (EMBL-EBI) and Partners set up the } \\
\text { Covid-19 biomedical data sources }\end{array}$ \\
\hline 10 & CDC Library, USA & Centers for Disease Control and Prevention, Downloadable database of Covid-19 \\
\hline 11 & Amazon AWS & Public data lake centralized repository \\
\hline 12 & $\begin{array}{l}\text { Semantic Scholar Covid- } \\
\quad 19\end{array}$ & $\begin{array}{l}\text { Covid-19 Open Research Dataset is designed by Allen Institute for AI, a free resource of about 130,000 } \\
\text { scholarly articles }\end{array}$ \\
\hline 13 & Aitslab_Covid-19 & NLP toolbox repository for Covid-19 research \\
\hline 14 & AI against Covid-19 & Information related to Genomics, Datasets, Research articles and NLP source data \\
\hline 15 & HealthMap Covid-19 & Visualization of Covid-19 with the help of global map \\
\hline 16 & Worldometer & Real-time online tracking system of Covid-19 cases \\
\hline
\end{tabular}

Table 3 Top 10 countries in cases on Covid-19 pandemic $[12,13]$

\begin{tabular}{llllrl}
\hline S. no. & Country & Confirmed cases & Recovered cases & Deaths & Active cases \\
\hline 1 & USA & $5,746,534$ & $2,473,186$ & 177,438 & $2,473,186$ \\
2 & Brazil & $3,505,097$ & $2,653,407$ & 112,423 & 739,267 \\
3 & India & $2,910,032$ & $2,160,059$ & 55,002 & 694,971 \\
4 & Russia & 946,976 & 761,330 & 16,189 & 169,457 \\
5 & South Africa & 599,940 & 497,169 & 12,618 & 90,153 \\
6 & Peru & 567,059 & 380,730 & 27,034 & 159,295 \\
7 & Mexico & 543,806 & 371,638 & 59,106 & 113,062 \\
8 & Colombia & 513,719 & 339,124 & 16,183 & 158,412 \\
9 & Spain & 404,229 & N/A & 28,813 & N/A \\
10 & Chile & 391,849 & 366,063 & 10,671 & 15,115 \\
\hline
\end{tabular}

$N A$ not available

require automated systems and health care workers in abundance. Figure 3 Shows the graphical view of Covid-19 death cases globally [75]. Figure 4 shows Covid-19 death cases in WHO regions from 30th December 2019 to 1st September 2020 graphically which shows a clear upward trend as time passes [75].

\section{Research methodology}

\subsection{Data description}

In this paper, Covid-19 confirmed and death cases of India are taken from World Health Organization [73] as on 1st September 2020. Data for experimentation is taken from the day when first case was taken into consideration in the country. Confirmed cases are taken from 29th January to 




$10,000+$

$1,000-10,000$

$100-1,000$

$10-100$

$1-10$

0

No Reported Data

Not Applicable

Fig. 3 Covid-19 death cases worldwide as on 1st September 2020

Americas
Europe
South-East Asia
Africa
Western Pacific
Source: World Health Organization
Wh Data may be incomplete to the current day or week

$$
\begin{array}{r}
430,964 \\
\text { deaths } \\
215,365 \\
\text { deaths } \\
65,314 \\
\begin{array}{r}
6 \text { deaths } \\
47,549 \\
\text { dea:hs } \\
19,557 \\
\text { deaths } \\
9,741 \\
9,741 \\
\text { deaths }
\end{array}
\end{array}
$$

Fig. 4 Covid-19 death cases in WHO region from 30th December to 1st September 2020

Fig. 5 Proposed deep-LSTM ensemble model

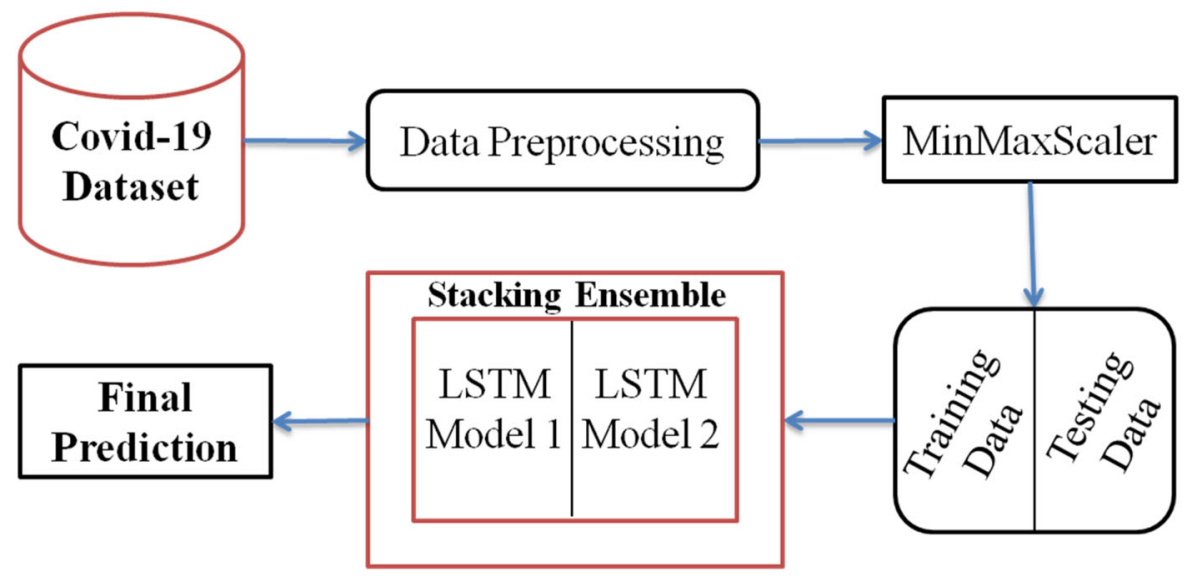

1st September 2020 and death cases are taken from 12th March to 1st September 2020.

\subsection{Experiment}

The experiments are carried out in Google Colaboratory using python 3.0 with open source libraries like 
Table 4 Classification metrics on Indian Covid-19 confirmed and death cases

\begin{tabular}{|c|c|c|c|c|c|c|}
\hline S. no. & Country & Accuracy & Precision & Recall & F-measure & MAPE \\
\hline & \multicolumn{6}{|c|}{ deep-LSTM ensemble model on Covid-19 confirmed cases } \\
\hline \multirow[t]{2}{*}{1} & India & 97.59 & 100 & 97.14 & 0.98 & 2.40 \\
\hline & & \multicolumn{5}{|c|}{ deep-LSTM ensemble model on Covid-19 death cases } \\
\hline 2 & & 98.88 & 98.73 & 100 & 0.99 & 1.11 \\
\hline
\end{tabular}

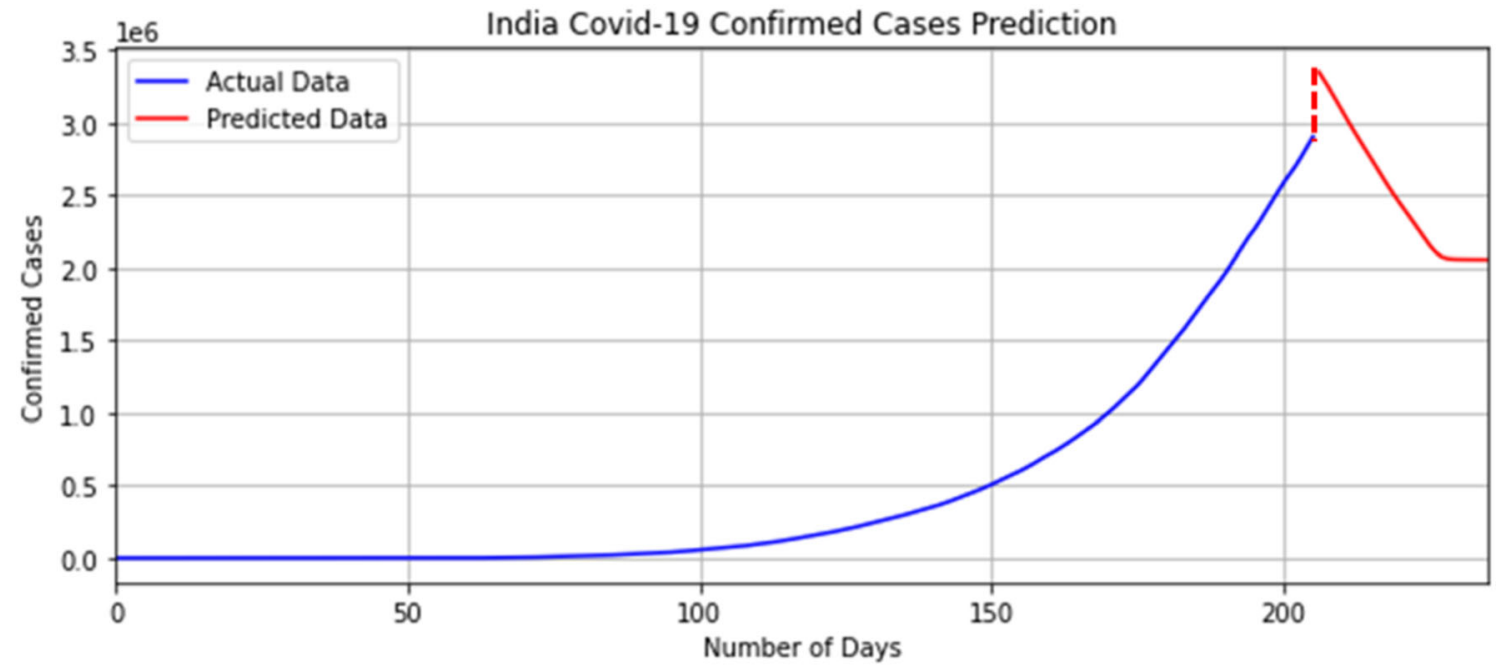

Fig. 6 India Covid-19 confirmed cases prediction



Fig. 7 India Covid-19 death cases prediction

Tensorflow, Pandas, Numpy, and keras. The experimental setup is based on working environment having Intel(R) Core (TM) i5-7400 CPU @ $3.00 \mathrm{GHz}$ with 4 GB RAM under 64-bit Windows 10 pro Operating system. Various time series techniques can be used to forecast the data which includes long short term memory and exponential smoothing [74]. We have proposed a nested ensemble model using deep learning based long short term (LSTM) models as shown in Fig. 5. The deep-LSTM ensemble model using convolutional and bi-directional LSTM gives state-of-the-art results and designed the high accuracy model to forecast Covid-19. The dataset used for experimentation is divided into training and testing phases as $70 \%$ of data is used for training and $30 \%$ of it is used for testing purpose. The tuning of hyper-parameters is set after rigorous testing at each stage. MinMaxScaler is used to scale the data between $(-1,1)$ to make it fit for experimentation. Results are compared in terms of accuracy, 
Table 5 Author's contribution on Covid-19

\begin{tabular}{|c|c|c|c|c|}
\hline $\begin{array}{l}\text { S. } \\
\text { no. }\end{array}$ & Authors & Data & Methods & Results \\
\hline 1 & Lin et al. [76] & $\begin{array}{l}4356 \text { chest CT exams from } 3322 \text { patients. Final dataset } \\
\text { consists of } 1296 \text { Covid-19 exams, } 1735 \text { for CAP and } \\
1325 \text { for non-pneumonia }\end{array}$ & $\begin{array}{l}\text { Deep Learning } \\
\text { model- } \\
\text { COVNet }\end{array}$ & AUC of 0.96 for detecting Covid-19 \\
\hline 2 & Maghdid et al. [77] & $361 \mathrm{CT}$ images and $170 \mathrm{X}$-ray images & $\begin{array}{l}\mathrm{CNN} \text { and } \\
\text { AlexNet }\end{array}$ & $\begin{array}{l}\text { Accuracy of } 94.1 \% \text { for } \mathrm{CT} \text { and } 98 \% \\
\text { for X-ray }\end{array}$ \\
\hline 3 & Ghoshal et al. [78] & $\begin{array}{l}\text { Normal: } 1583 \text {, bacterial pneumonia: } 2786 \text {, non-COVID19 } \\
\text { viral pneumonia: } 1504 \text {, and COVID-19: } 68 \text {, total } 5941 \\
\text { posterior-anterior chest radiography images }\end{array}$ & $\mathrm{CNN}$ & $89.92 \%$ of accuracy \\
\hline 4 & Gozes et al. [79] & 157 patients from US and China & ResNet-50 & AUC of 0.996 \\
\hline 5 & Wang et al. [80] & $\begin{array}{l}\text { Total } 1065 \text { CT images—confirmed COVID- } 19 \text { cases } 325 \\
\text { images and viral pneumonia } 740 \text { images }\end{array}$ & InceptionNet & $\begin{array}{l}89.5 \% \text { accuracy, } 0.88 \text { specificity } \\
\text { and } 0.87 \text { sensitivity }\end{array}$ \\
\hline 6 & $\begin{array}{l}\text { Chenthamarakshan } \\
\text { et al. [81] }\end{array}$ & $\begin{array}{l}250 \mathrm{k} / 10 \mathrm{k} / 10 \mathrm{k} \text { molecules (training/test/scaffold test sets) } \\
\text { from ZINC database }\end{array}$ & $\begin{array}{l}\text { Generative } \\
\text { models }\end{array}$ & $\begin{array}{l}\text { Released } 3000 \text { novel COVID-19 } \\
\text { drug candidates }\end{array}$ \\
\hline 7 & Chen et al. [82] & $\begin{array}{l}\text { 46,096 CT images from } 106 \text { patients-51 Covid-19 } \\
\text { confirmed and } 55 \text { other viral diseases }\end{array}$ & UNet ++ & $\begin{array}{l}95.24 \% \text { of accuracy, } 100 \% \\
\text { sensitivity and } 93.55 \% \text { specificity }\end{array}$ \\
\hline 8 & $\begin{array}{l}\text { Apostolopoulos } \\
\text { et al. [83] }\end{array}$ & $\begin{array}{l}\text { Collected } 1427 \text { X-ray images-224 Covid-19 patients, } 700 \\
\text { common viral pneumonia, } 504 \text { normal }\end{array}$ & $\begin{array}{l}\text { Transfer } \\
\text { learning CNN }\end{array}$ & $\begin{array}{l}96.78 \% \text { accuracy, } 98.66 \% \\
\text { sensitivity, and } 96.46 \% \text { specificity }\end{array}$ \\
\hline 9 & Yamac et al. [84] & $\begin{array}{l}\text { A QaTa-Cov19 dataset containing over } 6200 \mathrm{X} \text {-ray images } \\
\text { is created }\end{array}$ & CheXNet DNN & $\begin{array}{l}98.00 \% \text { sensitivity and } 95.00 \% \\
\text { specificity }\end{array}$ \\
\hline 10 & Jin et al. [85] & $\begin{array}{l}970 \mathrm{CT} \text { volumes of } 496 \text { Covid-19 patients and } 1385 \text { normal } \\
\text { cases }\end{array}$ & DCNN & $94.98 \%$ accuracy and $97.91 \%$ AUC \\
\hline 11 & Farooq et al. [86] & 5941 chest radiography images from 2839 patients & COVID-ResNet & $\begin{array}{l}\text { Accuracy of } 96.23 \% \text {, sensitivity, } \\
\text { precision and } \mathrm{F} 1 \text { measure are } \\
100 \%\end{array}$ \\
\hline 12 & Sethy et al. [87] & 25 Covid-19 X-ray image & CNN models & $\begin{array}{l}\text { Accuracy of } 95.38 \%, \text { F1-score } \\
91.41 \% \text { and MCC of } 90.76 \%\end{array}$ \\
\hline 13 & $\begin{array}{l}\text { Barstugan et al. } \\
\text { [88] }\end{array}$ & 150 CT images from 53 Covid- 19 patients & $\begin{array}{l}\text { SVM with } \\
\text { feature } \\
\text { extraction } \\
\text { methods }\end{array}$ & $\begin{array}{l}\text { Accuracy of } 99.68 \% \text { with tenfold } \\
\text { CV and GLSZM features } \\
\text { extraction method }\end{array}$ \\
\hline 14 & Jin et al. [89] & $\begin{array}{l}\text { Dataset from } 5 \text { hospitals: } 1136 \text { cases with } 723 \text { Covid-19 } \\
\text { positive }\end{array}$ & $\begin{array}{l}\text { UNet }++ \text { and } \\
\text { ResNet-50 }\end{array}$ & $\begin{array}{l}97.40 \% \text { sensitivity and } 92.20 \% \\
\text { specificity }\end{array}$ \\
\hline 15 & Wang et al. [90] & Dataset of 13,975 CXR images from 13,870 patients & Covid-Net & $\begin{array}{l}\text { Accuracy of } 93.30 \% \text {, sensitivity of } \\
91.00 \%\end{array}$ \\
\hline 16 & Shastri et al. [91] & Covid-19 India and USA confirmed and death cases & $\begin{array}{l}\text { RNN based } \\
\text { LSTM } \\
\text { methods }\end{array}$ & $\begin{array}{l}\text { Accuracy of } 97.82 \% \text { and } 98.00 \% \\
\text { for confirmed cases of India and } \\
\text { USA respectively }\end{array}$ \\
\hline 17 & Proposed method & India Covid-19 confirmed and death cases & $\begin{array}{l}\text { deep-LSTM } \\
\text { ensemble } \\
\text { model }\end{array}$ & $\begin{array}{l}\text { Accuracy of } 97.59 \% \text { and } 98.88 \% \\
\text { for confirmed and death cases } \\
\text { respectively }\end{array}$ \\
\hline
\end{tabular}

precision, recall and F-measure. The error in the model is calculated in terms of mean absolute percentage error (MAPE) as shown in Table 4. We forecasted the Covid-19 confirmed and death cases for one month ahead as is shown graphically in Figs. 6 and 7.

The forecasted Covid-19 confirmed cases of India shows significant upward trend for some more time in near future. The actual (blue line) and predicted (red line) data is visualized in Fig. 6 having some sudden jump (red dotted line) in the forecasted data also. Significant downward trend is shown after some time in Covid-19 predicted confirmed cases. Figure 7 shows Covid-19 actual (blue line) and predicted (red line) cases for one month ahead, showing a significant downward trend in death cases at the end of the month.

\section{Author contributions using AI applications}

This section summarizes working of Covid-19 datasets with AI assisted systems to diagnose this pandemic. Through extensive literature survey we came to know 
various models and methods of different researchers on Covid-19 shown in Table 5.

\section{Conclusion and future work}

Artificial intelligence is the key concept for all diseases including coronavirus. It can monitor the health care services to easily detect, prevent and diagnose the Covid-19 pandemic. AI assisted intelligent medical imaging aimed at coronavirus is the key factor to diagnose this pandemic. In this paper, we take a deep insight to the pandemic in terms of sources of information and also designed an experimental study using proposed deep-LSTM ensemble model to diagnose Covid-19. We carry out our experimentation for Covid-19 confirmed and death cases of India. Various classification metrics are used to check efficiency of proposed model with error rate. For Covid-19 confirmed cases we achieved an accuracy of $97.59 \%$ and for death cases it is $98.88 \%$. MAPE value for both the experiments aimed Covid-19 confirmed and death cases are 2.40 and 1.11 respectively.

In the future, we can forecast Covid-19 cases for different countries with comparative analysis. As the Covid19 cases are increasing exponentially it is impossible to defeat this pandemic without the inception of Artificial Intelligence that can help in proper treatment, prevention and vaccine development. Therefore, we can compare the leading technologies and vaccines used or developed by various countries to recede Covid-19 impacts and enhance its future time line.

Funding No funding sources.

Compliance with ethical standards

Conflict of interest None declared.

\section{References}

1. Kumar D, Malviya R, Sharma PK (2020) CoronaVirus: a review of COVID-19. EJMO 4(1):8-25. https://doi.org/10.14744/ejmo. 2020.51418

2. Centers for Disease Control and Prevention (CDC) (2003) Update: outbreak of severe acute respiratory syndrome-worldwide, 2003. MMWR Morb Mortal Wkly Rep 52(12):241-6.

3. Peiris JSM, Lai ST, Poon LL, Guan Y, Yam LY, Lim W et al (2003) Coronavirus as a possible cause of severe acute respiratory syndrome. Lancet 361:1319-1325. https://doi.org/10.1016/ S0140-6736(03)13077-2

4. Harapan H, Itoh N, Yufika A, Winardi W, Keam S, Te H et al (2020) Coronavirus disease 2019 (COVID-19): a literature review. J Infect Public Health. https://doi.org/10.1016/j.jiph. 2020.03.019
5. Kaul D (2020) An overview of coronaviruses including the SARS-2 coronavirus e molecular biology, epidemiology and clinical implications. Curr Med Res Pract 10:54-64. https://doi. org/10.1016/j.cmrp.2020.04.001

6. Hassan S, Sheikh FN, Jamal S, Ezeh JK, Akhtar A (2020) Coronavirus (COVID-19): a review of clinical features, diagnosis, and treatment. Cureus 12(3):e7355. https://doi.org/10.7759/ Fcureus. 7355

7. Singhal T (2020) A review of coronavirus disease-2019 (COVID19). Indian J Pediatr 87(4):281-286. https://doi.org/10.1007/ s12098-020-03263-6

8. Ali SA, Baloch M, Ahmed N, Ali AA, Iqbal A (2020) The outbreak of coronavirus disease 2019 (COVID-19)—an emerging global health threat. J Infect Public Health 13(4):644-646. https:// doi.org/10.1016/j.jiph.2020.02.033

9. Zhang R, Wang X, Ni L, Dia X, Maa B, Niu S et al (2020) COVID-19: melatonin as a potential adjuvant treatment. Life Sci 250:117583. https://doi.org/10.1016/j.lfs.2020.117583

10. Chawla S, Mittal M, Chawla M, Goyal LM (2020) CoronaVirus-SARS-CoV-2: an insight to another way of natural disaster. EAI Endorsed Trans Pervasive Health Technol. https:// doi.org/10.4108/eai.28-5-2020.164823

11. Unhale SS, Ansar QB, Sanap S, Thakhre S, Wadatkar S, Bairagi $\mathrm{R}$ et al (2020) A review on CoronaVirus (COVID-19). World J Pharm Life Sci 6(4):109-115

12. Wordometer Website. https://www.worldometers.info/cor onavirus/coronavirus-death-rate/. Accessed 2 Sept 2020

13. John Hopkins University Covid-19 Dashboard. https://www.arc gis.com/apps/opsdashboard/index.html\#/ bda7594740fd40299423467b48e9ecf6. Accessed 2 Sept 2020

14. Vaishya R, Javaid M, Khan IH, Haleem A (2020) Artificial intelligence (AI) applications for COVID-19 pandemic. Diabetes Metab Syndrome 14:337-339. https://doi.org/10.1016/j.dsx.2020. 04.012

15. Kursumovic E, Lennane S, Cook TM (2020) Deaths in healthcare workers due to COVID-19: the need for robust data and analysis. Anaesthesia. https://doi.org/10.1111/anae.15116

16. Hadley TD, Pettit RW, Malik T, Khoei AA, Salihu HM (2020) Artificial intelligence in global health-a framework and strategy for adoption and sustainability. Int J Maternal Child Health AIDS 9(1):121-127. https://doi.org/10.21106/ijma.296

17. Penga Z, Wang J, Moa Y, Duana W, Xianga G, Yi M et al (2020) Unlikely SARS-CoV-2 vertical transmission from mother to child: a case report. J Infect Public Health 13:818-820. https:// doi.org/10.1016/j.jiph.2020.04.004

18. Pourhomayoun M, Shakibi M (2020) Predicting mortality risk in patients with COVID-19 using artificial intelligence to help medical decision-making. medRxiv preprint. https://doi.org/10. 1101/2020.03.30.20047308

19. Hu Z, Ge Q, Li S, Jin L, Xiong M (2020) Artificial intelligence forecasting of Covid-19 in China. arXiv: Other Quantitative Biology

20. Dong E, Du H, Gardner L (2020) An interactive web-based dashboard to track COVID-19 in real time. Lancet Infect Dis. https://doi.org/10.1016/S1473-3099(20)30120-1

21. John Hopkins University Website. https://systems.jhu.edu/ research/public-health/ncov/. Accessed 1 Sept 2020

22. HealthMap Dashboard. https://www.healthmap.org/covid-19/. Accessed 1 Sept 2020

23. Xu B, Kraemer MUG (2020) Open access epidemiological data from the COVID-19 outbreak. Lancet Infect Dis. https://doi.org/ 10.1016/S1473-3099(20)30119-5

24. World Health Organization Website. https://covid19.who.int/. Accessed 1 Sept 2020

25. Noll NB, Aksamentov I, Druelle V, Badenhorst A, Ronzani B, Jefferies $G$, et al. COVID-19 Scenarios: an interactive tool to 
explore the spread and associated morbidity and mortality of SARS-CoV-2, medRxiv preprint 2020, https://doi.org/10.1101/ 2020.05.05.20091363.

26. Covid-19 Scenarios Web Application, University of Basel. https://covid19-scenarios.org/. Accessed 1 Sept 2020.

27. GitHub Repository. https://github.com/neherlab/covid19_scenar ios. Accessed 1 Sept 2020

28. Covid-19 Forecast Web Application, The University of Melbourne. http://covid19forecast.science.unimelb.edu.au/. Accessed 1 Sept 2020

29. GitHub Repository. https://github.com/benflips/nCovForecast. Accessed 14 June 2020

30. Mercatelli D, Triboli L, Fornasari E, Ray F, Giorgi FM (2020) coronapp: a web application to annotate and monitor SARS-CoV2 mutations. bioRxiv preprint. https://doi.org/10.1101/2020.05. 31.124966

31. COVID-19 genome annotator Web Application. http://giorgilab. dyndns.org/coronapp/. Accessed 28 Aug 2020

32. GitHub Repository. https://github.com/federicogiorgi/giorgilab/ tree/master/coronapp. Accessed 28 Aug 2020

33. Imran A, Posokhova I, Qureshi HN, Masood U, Riaz S, Ali K et al (2020) AI4COVID-19: AI enabled preliminary diagnosis for COVID-19 from cough samples via an App. arXiv:2004.01275

34. Li X, Zhu D (2020) Covid-xpert: an AI powered population screening of covid-19 cases using chest radiography images. arXiv:2004.03042

35. Ji Y, Ma Z, Peppelenbosch MP, Pan Q (2020) Potential association between COVID-19 mortality and health-care resource availability. Lancet Glob Health. https://doi.org/10.1016/S2214109X(20)30068-1

36. Mei X, Lee HC, Diao KY, Huang M, Lin B, Chenyu L et al (2020) Artificial intelligence-enabled rapid diagnosis of patients with COVID-19. Nat Med. https://doi.org/10.1038/s41591-0200931-3

37. Abbas A, Abdelsamea MM, Gaber MM (2020) Classification of COVID-19 in chest X-ray images using DeTraC deep convolutional neural network. medRxiv preprint. https://doi.org/10.1101/ 2020.03.30.20047456

38. Ke YY, Peng TT, Yeh TK, Huang WZ, Chang SE, Wu SH et al (2020) Artificial intelligence approach fighting COVID-19 with repurposing drugs. Biomed J. https://doi.org/10.1016/j.bj.2020. 05.001

39. Wang Z, Wang G, Huang B, Xiong Z, Hong Q, Wu H et al (2020) Masked face recognition dataset and application. arXiv:2003. 09093

40. Narin A, Kaya C, Pamuk Z (2020) Automatic detection of coronavirus disease (COVID-19) using X-ray images and deep convolutional neural networks. arXiv:2003.10849

41. Wang Y, Hu M, Li Q, Zhang XP, Zhai G, Yao N (2020) Abnormal respiratory patterns classifier may contribute to largescale screening of people infected with COVID-19 in an accurate and unobtrusive manner. arXiv:2002.05534

42. Khan AI, Shah JL, Bhat MM (2020) CoroNet: a deep neural network for detection and diagnosis of COVID-19 from chest X-ray images. Comput Methods Programs Biomed. https://doi. org/10.1016/j.cmpb.2020.105581

43. Gozes O, Frid-Ada M, Greenspan H, Browning PD, Zhang H, Ji $\mathrm{W}$ et al (2020) Rapid AI development cycle for the coronavirus (COVID-19) pandemic: initial results for automated detection \& patient monitoring using deep learning CT image analysis, pp 1-19. arXiv:2003.05037

44. Shan F, Gao Y, Wang J, Shi W, Shi N, Han M et al (2020) Lung infection quantification of COVID-19 in CT images with deep learning, pp 1-19. arXiv:2003.04655
45. Hamimi A (2016) MERS-CoV: Middle East respiratory syndrome coronavirus: can radiology be of help? Initial single center experience. Egypt J RadiolNucl Med 47(1):95-106

46. Gutiérrez Y, Ott D, Töpperwien M, Salditt T, Scherber C (2018) $\mathrm{X}$-ray computed tomography and its potential in ecological research: a review of studies and optimization of specimen preparation. EcolEvolut 8:7717-7732. https://doi.org/10.1002/ Fece3.4149

47. Swayamsiddha S, Mohanty C (2020) Application of cognitive Internet of Medical Things for COVID-19 pandemic. Diabetes Metab Syndrome. https://doi.org/10.1016/j.dsx.2020.06.014

48. Nguyen TT (2020) Artificial intelligence in the battle against coronavirus (COVID-19): a survey and future research directions. Preprint. https://doi.org/10.13140/RG.2.2.36491.23846

49. Ting DSW, Carin L, Dzau V, Wong TY (2020) Digital technology and COVID-19. Nat Med 26(4):459-461. https://doi.org/ 10.1038/s41591-020-0824-5

50. Sood SK, Mahajan I (2017) Wearable IoT sensor-based healthcare system for identifying and controlling chikungunya virus. Comput Ind 91:33-44. https://doi.org/10.1016/j.compind.2017. 05.006

51. Naudé W (2020) Artificial intelligence vs COVID-19: limitations, constraints and pitfalls. AI Soc. https://doi.org/10.1007/ s00146-020-00978-0

52. Kinsa Health, U.S. Health Weather Map 2020. https:// healthweather.us/?mode=Atypical. Accessed 26 Aug 2020

53. NPGEO, Dataset of infections in Germany 2020. https://npgeocorona-npgeo-de.hub.arcgis.com/datasets/dd4580c810204019a7 b8eb3e0b329dd6_0/data. Accessed 10 June 2020

54. SIRM, Covid-19-BSTI Imaging Database 2020. https://www.bsti. org.uk/training-and-education/covid-19-bsti-imaging-database/. Accessed 25 Aug 2020

55. SIRM, COVID-19 DATABASE 2020. https://www.sirm.org/ category/senza-categoria/covid-19/. Accessed 25 Aug 2020

56. nCoV2019Data, ncov2019 epidemiological data 2020. https:// github.com/beoutbreakprepared/nCoV2019. Accessed 26 Aug 2020

57. COVID-19 Korea Dataset with Patient Routes 2020. https:// github.com/ThisIsIsaac/Data-Science-for-COVID-19. Accessed 25 Aug 2020

58. NewYork-Times, New York times dataset 2020. https://github. com/nytimes/covid-19-data. Accessed 25 Aug 2020

59. Cohen JP, Morrison P, Dao L (2020) COVID-19 image data collection. arXiv:2003.11597. https://github.com/ieee8023/covidchestxray-dataset. Accessed 11 June 2020

60. Goodsell DS, Zardecki C, Di Costanzo L, Duarte JM, Hudson BP, Persikova I et al (2020) RCSB protein data bank: Enabling biomedical research and drug discovery. Protein Sci 29(1):52-65

61. MegSeg, COVID-19 CT segmentation dataset. http://medi calsegmentation.com/covid19/. Accessed 10 June 2020

62. Chen E, Lerman K, Ferrara E (2020) COVID-19: the first public Coronavirus Twitter dataset, arXiv:2003.07372

63. G. Inc. (2020) COVID-19 Community Mobility Reports. https:// www.google.com/covid19/mobility/. Accessed 25 August 2020

64. Sudalai RK (2020) Data, Novel corona-virus dataset. https:// www.kaggle.com/sudalairajkumar/novel-corona-virus-2019-data set. Accessed 29 August 2020

65. Allen-Institute (2020) CORD-19 research challenge. https:// www.kaggle.com/allen-institute-for-ai/CORD-19-research-chal lenge. Accessed 29 Aug 2020

66. NCBI (2020) LitCovid. https://www.ncbi.nlm.nih.gov/research/ coronavirus/. Accessed 29 Aug 2020

67. Chen Q, Allot A, Lu Z (2020) Keep up with the latest coronavirus research. Nature 579(7798):193. https://doi.org/10.1038/d41586020-00694-1 
68. ECDC (2020) European Centre for Disease Prevention and Control (ECDC). https://ourworldindata.org/coronavirus-sourcedata. Accessed 29 Aug 2020

69. CSSEGISandData (2020) CSSEGISandData/COVID-19. https:// github.com/CSSEGISandData/COVID-19. Accessed 30 Aug 2020

70. Smith (2020) Coronavirus (covid19) tweets. www.kaggle.com/ smid80/coronavirus-covid19-tweets. Accessed 30 Aug 2020

71. GISAID (2020) Genomic epidemiology of hCoV-19. https:// www.gisaid.org/epiflu-applications/next-hcov-19-app/. Accessed 30 Aug 2020

72. CHIME (2020) COVID-19 Hospital Impact Model for Epidemics. https://github.com/CodeForPhilly/chime. Accessed 28 Aug 2020

73. WHO (2020) Global research on novel coronavirus 2019. https:// www.who.int/emergencies/diseases/novel-coronavirus-2019/glo bal-research-on-novel-coronavirus-2019-ncov. Accessed 28 Aug 2020

74. Singh K, Shastri S, Bhadwal AS, Kour P et al (2019) Implementation of exponential smoothing for forecasting time series data. Int J Sci Res Comput Sci Appl Manag Stud

75. World Health Organization (2020) Covid-19 Situation Reports. https://www.who.int/emergencies/diseases/novel-coronavirus2019/situation-reports. Accessed 28 Aug 2020

76. Li L, Qin L, Xu Z, Yin Y, Wang X, Kong B et al (2020) Artificial intelligence distinguishes COVID-19 from community acquired pneumonia on chest CT. Radiology. https://doi.org/10.1148/ radiol.2020200905

77. Maghdid HS, Asaad AT, Ghafoor KZ, Sadiq AS, Khan MK (2020) Diagnosing COVID-19 pneumonia from X-ray and CT images using deep learning and transfer learning algorithms. arXiv:2004.00038

78. Ghoshal B, Tucker A (2020) Estimating uncertainty and interpretability in deep learning for coronavirus (COVID-19) detection. arXiv:2003.10769

79. Gozes O, Frid-Adar M, Greenspan H, Browning PD, Zhang H, Ji $\mathrm{W}$ et al (2020) Rapid AI development cycle for the coronavirus (COVID-19) pandemic: initial results for automated detection and patient monitoring using deep learning CT image analysis. arXiv:2003.05037

80. Wang S, Kang B, Ma J, Zeng X, Xiao M, Guo J et al (2020) A deep learning algorithm using CT images to screen for coronavirus disease (COVID-19). medRxiv. https://doi.org/10. 1101/2020.02.14.20023028

81. Chenthamarakshan V, Das P, Padhi I, Strobelt H, Lim KW, Hoover B et al (2020) Target-specific and selective drug design for covid-19 using deep generative models. arXiv:2004.01215

82. Chen J, Wu L, Zhang J, Zhang L, Gong D, Zhao Y et al (2020) Deep learning-based model for detecting 2019 novel Coronavirus pneumonia on high-resolution computed tomography: a prospective study. medRxiv. https://doi.org/10.1101/2020.02.25. 20021568

83. Apostolopoulos ID, Mpesiana TA (2020) Covid-19: automatic detection from $\mathrm{x}$-ray images utilizing transfer learning with convolutional neural networks. PhysEngSci Med. https://doi.org/ 10.1007/s13246-020-00865-4

84. Yamac M, Ahishali M, Degerli A, Kiranyaz S, Chowdhury MEH, Gabbouj M (2020) Convolutional sparse support estimator based Covid-19 recognition from X-ray images. arXiv:2005.04014v1 [eess.IV]

85. Jin C, Chen W, Cao Y, Xu Z, Zhang X, Deng L et al (2020) Development and evaluation of an AI system for COVID-19. medRxiv. https://doi.org/10.1101/2020.03.20.20039834

86. Farooq M, Hafeez A (2020) COVID-ResNet: a deep learning framework for screening of COVID19 from radiographs. arXiv: 2003.14395

87. Sethy PK, Behera SK (2020) Detection of coronavirus disease (covid19) based on deep features. Preprints. https://doi.org/10. 20944/preprints202003.0300.v1

88. Barstugan M, Ozkaya U, Ozturk S (2020) Coronavirus (covid-19) classification using ct images by machine learning methods. arXiv:2003.09424

89. Jin S, Wang B, Xu H, Luo C, Wei L, Zhao W et al (2020) AIassisted CT imaging analysis for COVID-19 screening: Building and deploying a medical AI system in four weeks. medRxiv. https://doi.org/10.1101/2020.03.19.20039354

90. Wang L, Lin ZQ, Wong A (2020) COVID-Net: a tailored deep convolutional neural network design for detection of COVID-19 cases from chest X-ray images. arXiv:2003.09871v4 [eess.IV]

91. Shastri S, Singh K, Kumar S, Kour P, Mansotra V (2020) Time series forecasting of covid-19 using deep learning models: IndiaUSA comparative case study. Chaos Solitons Fractals. https://doi. org/10.1016/j.chaos.2020.110227 